\title{
O ENSINO REMOTO EMERGENCIAL NOS CURSOS DE ENGENHARIA E TECNOLOGIA
}

DOI: 10.37702/2175-957X.COBENGE.2021.3714

Giovanni Falcão Mendes - giovannimendes800@gmail.com

Universidade Federal do Rio Grande do Sul

Rua Duque de Caxias, 15761576

90010-281 - Porto Alegre - RS

Simone Ramires - simone.ramires@ufrgs.br

Universidade Federal do Rio Grande do Sul

Praça Argentina 9

90040-020 - Porto Alegre - RS

Tiago de Oliveira Belmonte - belmontetiago0@gmail.com

Universidade Federal do Rio Grande do Sul

Rua Getúlio Vargas 810

95625-000 - Imbé - RS

Lucas dos Santos Azevedo - radialistalucasazevedo@outlook.com

Universidade Federal do Rio Grande do Sul

Rua José de Alencar 1318

90880-480 - Porto Alegre - RS

Ilka Maria de Oliveira Santi - ilkam@uol.com.br

FATEC Centro Paula Souza

R. Sena César Vergueiro 428

09641-020 - São Bernardo do Campo - SP

Carlos Eduardo Santi - prof.carlos.santi@gmail.com

Instituto Federal de Educação Ciência e Tecnologia de São Paulo

Rua Senador Cesar Vergueiro 428

09641-020 - São Bernardo do Campo - SP

Resumo: Com o advento da pandemia causada pela COVID-19 em 2020, as Instituições de Ensino Superior (IES) tiveram de adaptar-se para dar continuidade às atividades acadêmicas e implementar modelos de ensino para colocar em 
prática o que o Ministério da Educação (ME) denominou Ensino Remoto Emergencial (ERE).Os desafios impostos pela pandemia em 2020 foram um marco para docentes e instituições, principalmente no que se refere a propor e adaptar 0 ensino em cursos de Engenharia e Tecnologia, e impôs a necessidade imediata de tomar conhecimento e testar - no melhor de suas possibilidades - modelos implantados em diferentes instituições. Pretende-se, com este trabalho, discutir e avaliar se essas iniciativas foram bem-sucedidas, ou seja, se houve entendimento e bom rendimento de docentes e discentes sobre a nova forma de aprender e ensinar, de estudar e de planejar as disciplinas. Para tanto, foi realizado pesquisa através de questionário aplicado a diversas Instituições de Ensino Superior (IES) com total de 124 respondentes que possibilitou concluir que tanto o professor quanto $o$ aluno têm um potencial e responsabilidade de transformarem o ensino, além de alinharem e potencializarem o uso de inovações em aulas remota.

Palavras-chave: Educação. Engenharia. ERE. 


\section{O ENSINO REMOTO EMERGENCIAL NOS CURSOS DE ENGENHARIA E TECNOLOGIA}

\section{INTRODUÇÃO}

Com o advento da pandemia causada pela COVID-19 em 2020, as Instituições de Ensino Superior (IES) tiveram de adaptar-se para dar continuidade às atividades acadêmicas e implementar modelos de ensino para colocar em prática o que o Ministério da Educação (ME) denominou Ensino Remoto Emergencial (ERE). Os desafios impostos pela pandemia em 2020 foram um marco para docentes e instituições, principalmente no que se refere a propor e adaptar o ensino em cursos de Engenharia e Tecnologia, e impôs a necessidade imediata de tomar conhecimento e testar - no melhor de suas possibilidades - modelos implantados em diferentes instituições.

Pretende-se, com este trabalho, discutir e avaliar se essas iniciativas foram bemsucedidas, ou seja, se houve entendimento e bom rendimento de docentes e discentes sobre a nova forma de aprender e ensinar, de estudar e de planejar as disciplinas. Também pretende-se avaliar se os docentes, segundo Bruno-Faria et al (2013) conseguiram adaptar os currículos em função da nova demanda e de suas limitações, considerando o uso de tecnologias de apoio com adoção emergencial, considerando as características peculiares de cada região. Como exemplos, pode-se pensar na qualidade da Internet nas diversas localidades ou mesmo no ambiente de trabalho domiciliar, nem sempre devidamente preparado para acomodar a nova demanda que foi tornar-se a nova sala de aula. Deve-se levar em conta, o fato de que o atual momento era inimaginável para a sociedade, impôs desafios físicos, pedagógicos e até mesmo emocionais dos diversos envolvidos, para dar conta das mudanças repentinas na nova realidade.

Nesse sentido, com a implementação do ERE, as IES, por sua vez, tiveram de adaptar-se com adoção de novas tecnologias, melhorias na infraestrutura, seleção de plataformas, capacitação imediata para docentes quanto aos novos recursos utilizados, o mesmo para os discentes, tudo para implementar as disciplinas e manter a grade curricular durante a pandemia.

Em meio a tudo isso, surgiram produtivos debates por parte dos conselhos de ensino e pesquisa da IES para estruturar atividades ativas e reflexivas, projetos foram pensados para se encaixarem no novo método de aprendizagem, para motivar os alunos e diminuir a barreira virtual com atividades práticas e integrativas por meio de TICs (tecnologias da informação e comunicação). Algumas sinalizações positivas desse uso já apontam para um aproveitamento das atividades no chamado Ensino Híbrido, após a pandemia.

É importante salientar que os questionamentos ainda são muitos, mas é certo que o ERE desde já poderá contribuir para aperfeiçoar, refutar ou corroborar as metodologias ativas de aprendizagem, como a Aprendizagem Baseada em Problemas (PBL), a Sala de aula invertida (Flipped Classroom), entre outras que possivelmente foram utilizadas no novo cenário de aprendizagem. Ali, a despeito das limitações do momento, estimulam a autonomia dos estudantes, contando com suas habilidades de criatividade, trabalho em equipe, colaboração, raciocínio lógico e especialmente o espírito inovador. É importante destacar que é preciso desenvolver a habilidade de entender as características individuais dos envolvidos. Além disso, o estudo realizado por Zancul et al. (2018) será utilizado pelos pesquisadores envolvidos para apoiar as ferramentas utilizadas para a comunicação com os acadêmicos como síncrona e assíncrona.

As ferramentas síncronas permitem a comunicação on-line e imediata, como chat e videoconferência, enquanto nas ferramentas assíncronas, não é necessária a participação dos envolvidos ao mesmo tempo, tais como fóruns e e-mails. 
Neste cenário, o docente teve a responsabilidade de estimular os alunos a buscar soluções para os problemas do mundo real, instigá-los a aprender e propor alternativas para melhorar a interação, sem deixar de atentar às desigualdades sociais, ainda reais no país (SILVEIRA, 2005). Dos discentes, exigiu-se uma nova postura e outras habilidades no que se refere ao conhecimento e ao trato com os demais, um momento realmente de mudança de paradigmas. Além disso, com as restrições impostas pela Covid-19, foi preciso repensar as práticas pedagógicas e a introdução massiva da tecnologia no ambiente educacional, para que fosse possível promover a continuidade do ensino.

\section{ENSINO REMOTO EMERGENCIAL (ERE)}

O Ensino Remoto Emergencial e a Educação a Distância não podem ser compreendidos como sinônimos, por isso é muito importante, neste contexto, esclarecer esses conceitos (BEHAR, 2020). O ensino é considerado "remoto" porque professores e alunos se viram impedidos por decreto de frequentarem as instituições educacionais devido às medidas de restrição sanitária. Tornou-se "emergencial" porque do dia para noite o planejamento pedagógico para o ano letivo de 2020 teve que ser refeito a adaptado.

Além disso, para Schwetz et al. (2020) a EaD requer a construção de práticas que sustentem a gestão da distância pedagógica, sendo que esta proposta consiste em um processo que enfatiza a construção e a socialização do conhecimento.

No entanto para Hodges et al (2020) no modo ERE, por sua vez, caracterizou-se pela adaptação das aulas presenciais com 0 uso das TICs para estabelecer uma comunicação síncrona com os alunos e independentemente do tempo e do espaço, possa tornar-se agente de sua aprendizagem, devido ao uso de materiais diferenciados e meios de comunicação, que permitam a interatividade (síncrona ou assíncrona) e do trabalho colaborativo (MOREIRA; SCHLEMMER, 2020).

Alguns estudiosos argumentam que o ensino remoto representa uma medida contingencial (VU et al., 2020), outros defendem a transformação radical nos sistemas educacionais, estimulada pela pandemia e conduzida por inovações digitais (LIPOMI, 2020).

Ainda, modificou o ambiente no qual as relações de aprendizagem acontecem: as residências dos envolvidos no processo e trouxe a necessidade de mudanças nas competências de docentes e discentes para a vivência de uma experiência de aprendizagem significativa.

Para o estudante, é possível apenas "aparentar" uma presença que não existe, fazendo coro com um conjunto de câmeras fechadas, ou a opção por não assistir ao vídeo de aula inteira. Diante da necessidade massiva de recursos físicos, para a qual nem todos estavam preparados, inclusive economicamente, uma dificuldade que se tem é a de se diagnosticar até que ponto a dificuldade é de carência de recursos ou de desestímulo em relação à situação "livre", em um ambiente de sala de aula não controlado. Outro aspecto relevante para o ensino remoto é a dinâmica da aula, a qual, em função da transição do ambiente físico para o digital, acarretou mudanças nas interações de sala de aula (JOHNSON et al., 2020).

Nesse sentido, o estudo de Krishnamurthy (2020) destaca que esse contexto evidenciou a necessidade de se desenvolver novos modelos de aprendizado, fundamentados na utilização da tecnologia. Diante do novo cenário, de acordo com Schaefer e Minello (2016), há uma necessidade crescente de as universidades se adaptarem, pensarem em outras estratégias de ensino que permitam despertar em seus alunos, o engajamento e o espírito empreendedor (VERZAT; BACHELE, 2006). Neste 
sentido, fóruns, palestras, seminários e congressos podem, de alguma forma, ser a base de uma educação não somente motivadora, mas também empreendedora.

Como efeito, com a adoção de novas práticas, pode-se pensar em um novo diálogo entre docentes e discentes, apontando para uma aprendizagem mais criativa e significativa, a despeito de todas as limitações contra as quais ainda se luta.

\section{PROCEDIMENTOS METODOLÓGICOS}

Este artigo contempla uma pesquisa realizada pelo Núcleo de Ações Discentes (NADI) com estudantes de engenharia e tecnologia da Universidade Federal do Rio Grande do Sul e outras Instituições de Ensino Superior (IES) com objetivo de identificar a percepção dos estudantes sobre o Ensino Remoto Emergencial (ERE) e com os resultados comparar com outras IES para compartilhar resultados e saberes com o propósito de melhoria contínua.

Foi perguntada a IES à qual pertencia, curso, semestre, equipamentos disponíveis para assistir as aulas se os computadores e afins que têm acesso são dispositivos utilizados apenas para o seu uso pessoal ou necessita compartilhá-los com outras pessoa, quais atividades foram realizadas mais frequentemente, tipo de acesso a internet, avaliação das atividades realizadas, recursos utilizados são suficientes, dificuldades que enfrentou, frequência das aulas síncronas e por último sugestões para os próximo semestre que poderiam contribuir para a melhoria das aulas e das atividades didáticas.

O presente projeto de pesquisa utiliza metodologia de abordagem mista, sendo qualitativa no sentido que busca fazer uma análise da natureza do objeto de estudo (Ensino Remoto Emergencial), problemáticas envolvidas no contexto de seu uso (ambientais, sociais, de economia) com as relações dinâmicas de seu aproveitamento na atualidade. Quantitativa na medida que busca fazer uma análise quantitativa de dados obtidos por implementação de ferramentas estatísticas (FONSECA, 2002; GERHARDT, 2009).

Ainda, caracteriza-se como exploratória proporcionando maior familiaridade com o problema, com vistas à construção de hipóteses, como descritiva, no sentido que descreve e caracteriza conceitos, bem como explicativa, por analisar, verificar, avaliar, comparar e explicar os dados obtidos (GIL, 2007; MATTOS, 2019).

Sendo assim, constitui-se primeiramente de um estudo de caso de acordo com Yin (2015) que será realizado com foco no levantamento de dados, análise e implementação de melhorias no ERE nos cursos de Engenharia da Universidade Federal do Rio Grande do Sul (UFRGS) e demais Instituições de Ensino Superior (IES), viabilizando um processo de ensino mais dinâmico e eficiente utilizando metodologias de ensino a distância juntamente com a oferta de ensino presencial.

Ainda, de acordo com o autor caracteriza-se como estudo de caso, pois, investiga um fenômeno contemporâneo dentro do seu contexto de vida real, enfrentando uma situação única, com diversas variáveis e fontes de evidências e propondo melhoria contínua no processo ensino-aprendizagem.

\section{RESULTADOS E DISCUSSÕES}

No total de 124 respondentes das diversas IES do país, 62,1\% são estudantes da Universidade Federal do Rio Grande do Sul (UFRGS), 12,9\% da Universidade Federal do 
Mato Grosso (UFMT) e dos demais de outras IES como Universidade do Estado do Rio Grande do Sul (UERGS), Universidade de São Paulo (USP), Universidade Estácio de Sá e Universidade de Belo Horizonte (UniBH).

Percebe-se em relação ao semestre uma boa distribuição, conforme o gráfico 1 , sendo que a maioria dos respondentes se encontra no primeiro $13,7 \%$, segundo $23,4 \%$, terceiro $10,5 \%$ e oitavo semestre $12,1 \%$, caracterizando uma amostra homogênea.

Gráfico 1: Semestre cursado dentro dos cursos de engenharia

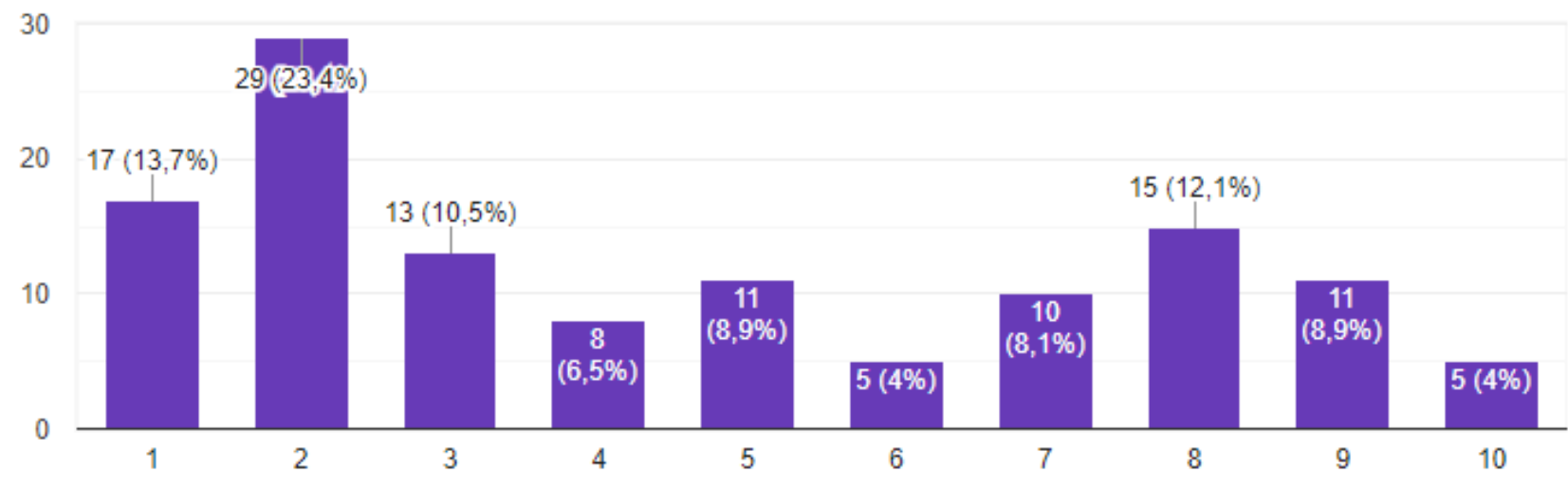

Quanto aos equipamentos que tem disponíveis para assistir aulas, gráfico 2, percebe-se que $91,9 \%$ possuem notebook, $87,9 \%$ smartphone, $80,6 \%$ fones de ouvido e $45,2 \%$ possuem câmera e quando é questionado sobre os computadores e afins são para uso pessoal e/ou compartilhados (gráfico 3) com outras pessoas, que você tem acesso são dispositivos utilizados apenas para o seu uso pessoal ou necessita compartilhá-los com outras pessoas, 83,9\% utilizam apenas para uso pessoal, enquanto que $16,1 \%$ compartilham com outras pessoas.

Gráfico 2: Equipamentos disponíveis para assistir às aulas

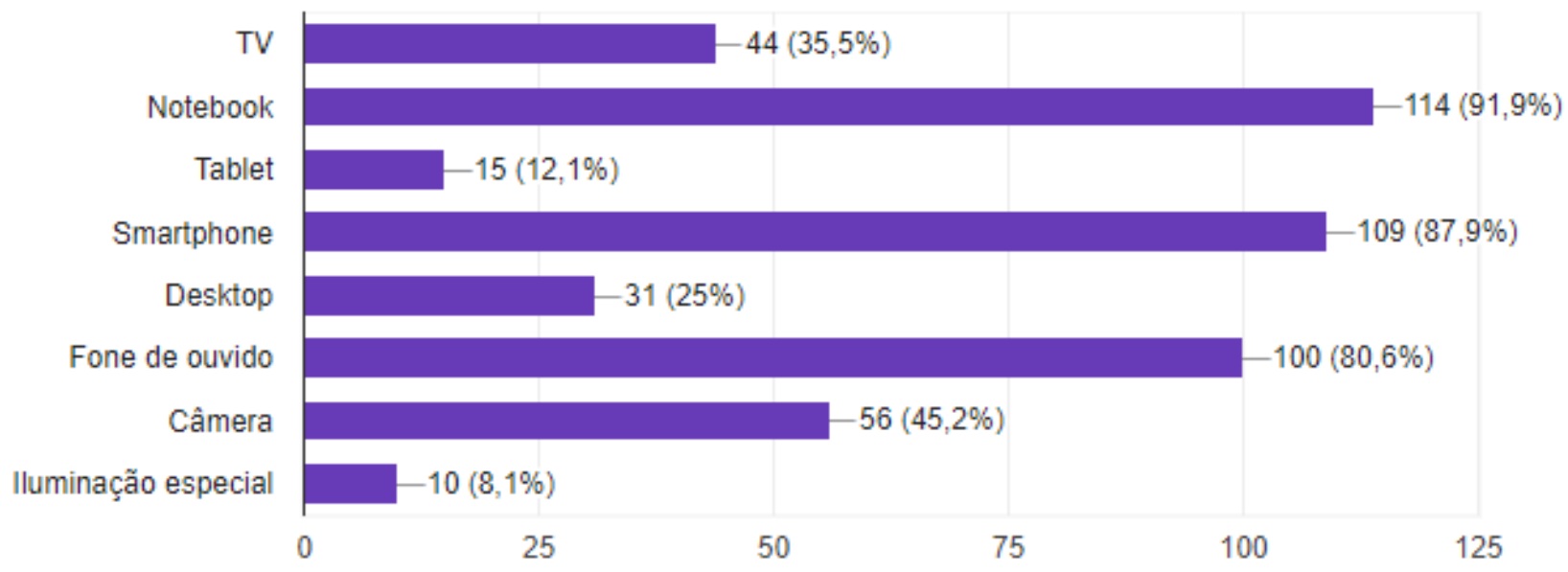




\section{COBENCE de Educação em Engenharic 2021 de Educaça \\ 28 a 30 de SETEMBRO \\ Evento Online \\ "Formação em Engenharia: \\ Tecnologia, Inovação e Sustentabilidade":}

Gráfico 3: percentual obtido referente ao uso individual ou compartilhado dos equipamentos

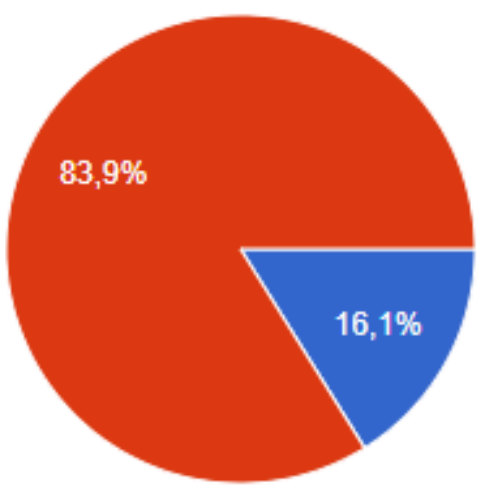

Compartilho com outras pessoas

Apenas para uso pessoal

Sobre as atividades realizadas com maior frequência em aula (gráfico 4), 39,5\% respondeu por por meio de atividades semanais, 33,1\% por vídeo aulas, 9,7\% por trabalhos individuais, $8,1 \%$ por trabalho em trabalho em grupo, 5,6\% por meio de exercícios, 2,4 por leituras, $0,8 \%$ por estudos dirigidos e $0,8 \%$ respondeu que depende da matéria.

Gráfico 4: Atividades mais frequentemente desenvolvidas por meio do ERE

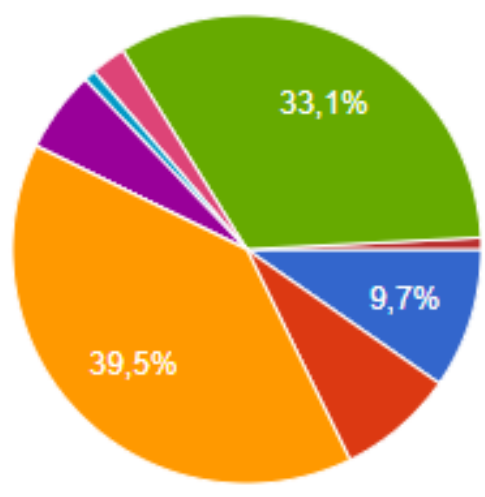

Trabalho individual

Trabalho em grupo

Atividade semanal

Atividade mensal

Exercícios

Estudos dirigidos

Textos e leituras

Videoaulas

- Depende da matéria pode ter mais uma modalida que outra. Mas de forma ger..

E, sobre ao tipo de acesso à internet (gráfico 5), 85,2\% informam ter acesso a internet à cabo, $6,6 \%$ por meio de radiofrequência, $5,7 \%$ através de roteamento de celular, 2,4\% outras formas ou não souberam responder.

Gráfico 5: Tipos de acesso a internet
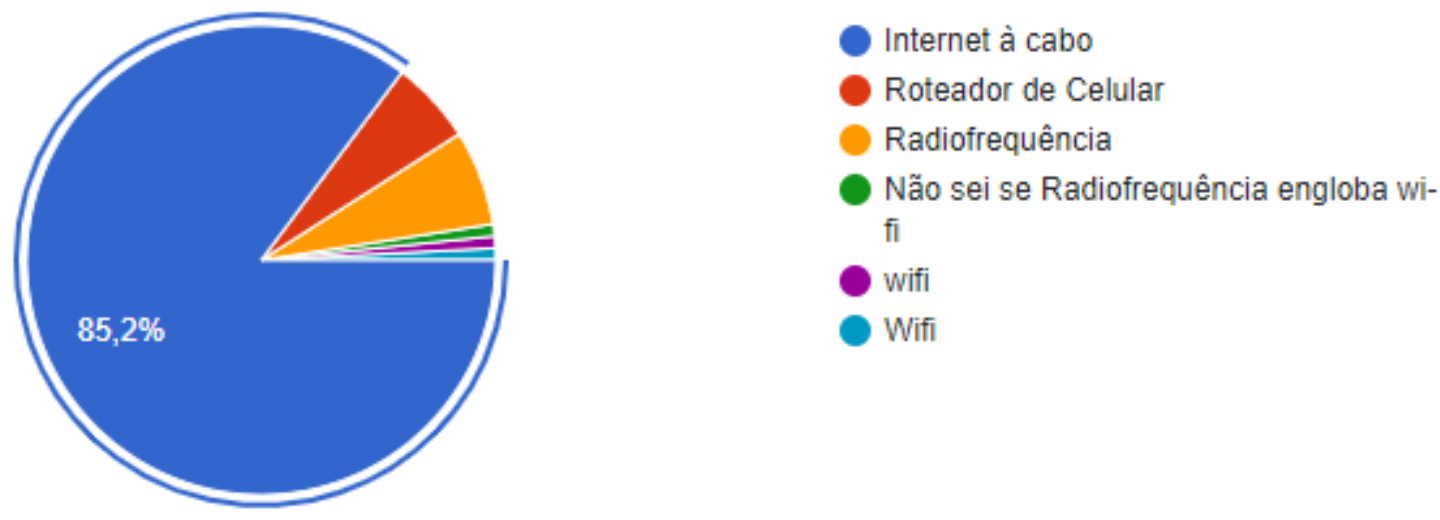
No quesito avaliação das atividades realizadas (gráfico 6), 48,4\% as considerou adequadas, $37,9 \%$ excessivas e $13,7 \%$ insuficientes.

Gráfico 6: Avaliação das atividades no ERE

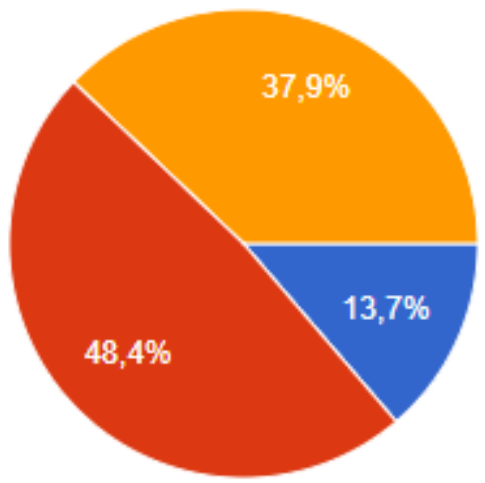

Insuficientes

Adequadas

Excessivas

Quando questionados se os recursos utilizados nas aulas são suficientes (gráfico 7), sendo de 1 a 5 a nota de satisfação (onde 1 representa que discorda totalmente e 5 que concordam totalmente), $4,1 \%$ deram nota $1,13 \%$ deram nota $2,37,4 \%$ deram nota $3,34,1 \%$ deram nota 4 e $11,4 \%$ deram nota 5 .

Gráfico 7: notas de satisfação quanto à suficiência dos recursos utilizados em aula

60

40

20

1

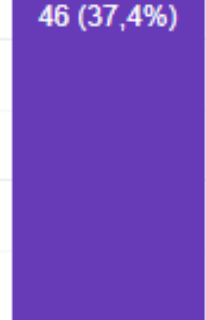

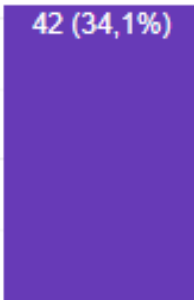

$14(11,4 \%)$

Referente as dificuldades enfrentadas durante o ERE (gráfico 8), 33,9\% informaram que é manter a disposição e controle da ansiedade, $32,3 \%$ a carga excessiva de trabalhos/atividades, $9,7 \%$ a falta de interação presencial com o professor, $8,1 \%$ a dinâmica de aulas e trabalhos, 4,8\% a falta de espaço próprio para estudar e realizar as atividades, $3,2 \%$ a distância da Universidade e $8 \%$ outras dificuldades.

Gráfico 8: Dificuldades enfrentadas no ERE

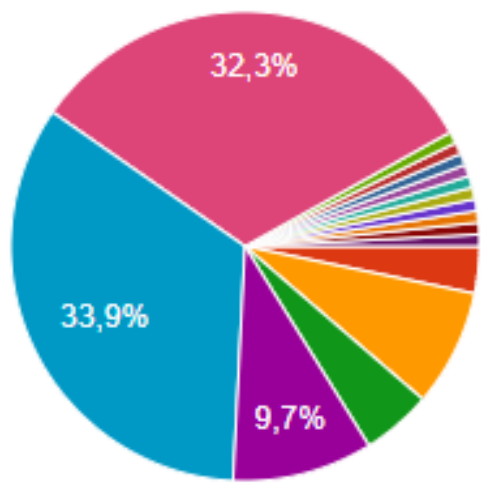

Acesso a equipamentos

Ficar distante da Universidade

Dinâmica de aulas e trabalhos

Não ter espaço próprio para estudar/r...

Falta de interação presencial com Pro..

Manter a disposição e controlar a ansi..

Carga excessiva de trabalhos/atividades

No caso o maior problema é o fato de.. 
Perguntado sobre nível de satisfação referente ao retorno e esclarecimento de dúvidas por parte do professor (gráfico 9), sendo avaliado de 1 a 5 (onde 1 discorda totalmente e 5 concorda totalmente), 7,3\% classificou o esclarecimento de dúvidas por parte do professor em nível de satisfação 1, 12,2\% em nível 2, 29,3\% em nível 3, 27,6\% em nível 4 e $23,6 \%$ em nível 5.

Gráfico 9: Eficiência no esclarecimento de dúvidas sobre as aulas

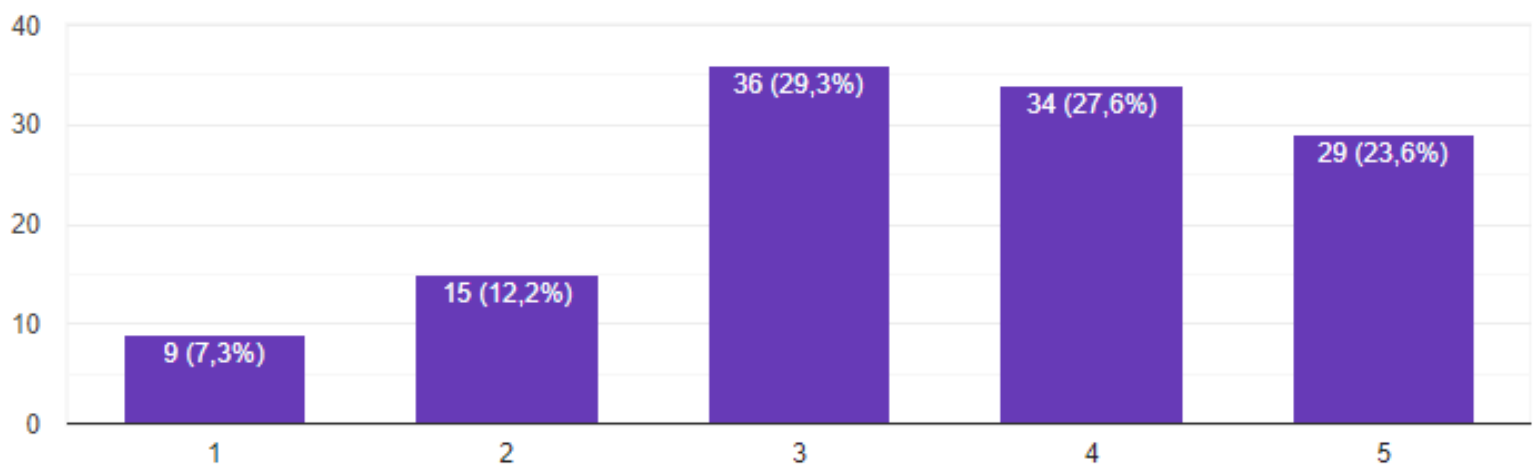

Quanto ao grau frequência dos alunos as aulas síncronas (gráfico 10), sendo avaliado de 1 a 5 (onde 1 representa que não frequentou e 5 que frequentou todas), 7,3\% avaliaram sua frequência em 1, 19,5\% em 2, 22\% em 3, 26,8\% em 4 e 24,4\% em 5.

Gráfico 10: Auto-avaliação de frequência dos alunos as aulas síncronas

40

30

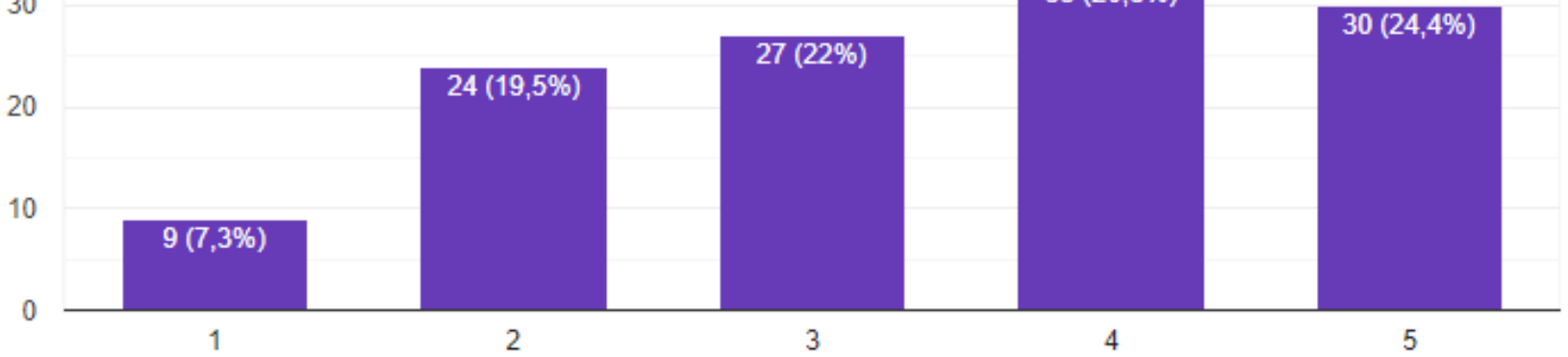

Como ponto importante no questionário refere-se a sugestões dos acadêmicos para o próximo semestre para melhorias das aulas e foi possível perceber desabafos por parte dos respondentes, tendo 52 respostas do total de 124, onde alguns percebem nos professores desânimo, além disso acreditam que está sendo difícil tanto para alunos quanto professores e que talvez possa aprender menos no modo ERE do que presencial e sugerem padronização dos métodos de avaliação e da divisão de notas para cada atividade.

Além das apontadas acima, houve sugestões como ter maiores períodos de aulas síncronas para poder tirar dúvidas, bem como diminuir a carga de atividades e padronização dos métodos de avaliação e da divisão de notas para cada atividade. 


\section{Considerações FINAIS}

Os resultados encontrados proporcionam o entendimento da percepção dos estudantes de engenharia com relação à importância dos fatores associados ao ensino remoto para o aprendizado e possibilita fornecer subsídios para auxiliar os professores da IES dos cursos de Engenharia a ministrarem suas aulas.

Ainda, é possível aferir que ao mesmo tempo representa um desafio aos estudantes e professores em muitas frentes, é uma oportunidade de desenvolvimento e adequação do uso de novas tecnologias, didáticas e fomento de pesquisas na área de ensino.

Dentre esses, há fatores importantes, como o engajamento, desempenho, atenção e preparação de toda a comunidade acadêmica para os novos moldes do ensino, bem como proporcionar o estímulo ao intercâmbio de conhecimento entre instituições de ensino superior a fim de obter melhores práticas na educação e, primordialmente, os potenciais de Inovação no ensinar nos cursos de Engenharia e Tecnologia.

Neste processo, é importante salientar que é necessário haver uma educação continuada de todos os docentes em relação às didáticas e metodologias de ensino, assim como o uso de tecnologias diversas para melhor integração e aprendizado dos estudantes.

Esses que, tanto no contexto do ensino presencial quanto no Ensino Remoto, precisam se sentir ativos em sua trajetória de construção de conhecimento, incluídas assim atividades que estimulem diferentes competências, habilidades e a criatividade. Além da pesquisa realizada pela UFRGS foi identificado que apenas $33,4 \%$ dos estudantes de Engenharia estavam satisfeitos ou muito satisfeitos com o ensino remoto emergencial.

Diante dos fatos e discussões expressas neste artigo, conclui-se que tanto o professor quanto o aluno têm um potencial e responsabilidade de transformarem o ensino, além de alinharem e potencializarem o uso de inovações em aulas remotas. Ademais, demarca-se que este ainda é um processo inicial, mas que propõe mudar a maneira de ensinar de forma permanente, mesmo pós-pandemia, dando base também para futuras soluções, como o Ensino Híbrido.

\section{REFERÊNCIAS}

A, M. V. O Mapeamento de conhecimentos em rede como estratégia de ensino e aprendizagem - uma visão ampliada de um AVA - Ambiente Virtual de Aprendizagem. Revista da ABENGE, vol. 39, № 1, 2018, pp. 13-25.

BITTENCOURT, I.M.; FERRAZ, E.S.; MERCADO, L.P.L. O uso de ferramenta síncrona na coleta de dados na pesquisa em educação online. Revista Ibero-Americana de Estudos em Educação. Araraquara, v.14, n.3, p. 1217-1228,jul./set.2019.

BRASIL, Ministério da Educação - Conselho Nacional de Educação - Diretrizes Nacionais Curriculares do Curso de Graduação em Engenharia. Parecer CNE $n^{\circ} 1 / 2019$. Disponível em: http://portal.mec.gov.br/index. php?option=com_docman\&view=download\&alias=109871-pces001-19-

1\&category_slug=marco-2019pdf\&Itemid =30192 Acesso em: set/2020.

BRASIL.Ministério da Educação. Coronavírus. Monitoramento nas instituições de ensino.Brasília, DF, MEC, 2020.Acesso em: 10 ago. 2020. Disponível em: http://portal.mec.gov.br/coronavirus/.Acesso em: 10 dez. 2020

BRUNO-FARIA, M. F., VARGAS, E. R., \& MARTÍNEZ, A. M. Criatividade e inovação nas organizações: desafios para a competitividade. São Paulo: Atlas, 2013. 
CORDEIRO, J. S. et al. Um futuro para a educação em engenharia no brasil: desafios e oportunidades. Revista de Ensino de Engenharia, v. 27, n. 3, p. 69-82, 2008.

CORRÊA, D. A.; NETO, M. S.; SPERS, V. R. E.; GIULIANI, A. C. Inovação, sustentabilidade e responsabilidade social: análise da experiência de uma empresa de equipamentos pesados. Revista de Gestão Social e Ambiental 4 (3), 90-105, 2010.

DEMO, Pedro; LAKATOS, Eva Maria; MARCONI, Marina de Andrade. Fundamentos de Metodologia Científica. São Paulo: Editora Atlas. 2009.

GIL, A. C. Métodos e técnicas de pesquisa social. 7. ed. São Paulo: Atlas, 2019.

GÜNTHER, Hartmut. Pesquisa Qualitativa versus pesquisa quantitativa: esta é a questão? Psicologia: Teoria e Pesquisa. Brasília, v. 22, n. 2, mai/ago, 2006, p. 201-210.

JOHNSON, N.; VELETSIANOS, G.; SEAMAN, J. U.S. faculty and administrators' experiences and approaches in the early weeks of the COVID-19 pandemic. Online Learning Journal, 24(2), p. 6-21, 2020.

KNIGHT, S.W.P. Establishing professional online communities for world language educators. Foreign Language Annals, 53(2), p. 298-305, 2020.

KRISHNAMURTHY, S. The future of business education: a commentary in the shadow of the covid-19 pandemic. Journal of Business Research, 117, p. 1-5, 2020.

LAKATOS, Eva Maria; MARCONI, Marina de Andrade. Fundamentos de Metodologia Científica. São Paulo: Editora Atlas. 1991.

LEMOS, Paulo Antônio Borges. As Universidades de Pesquisa e a Gestão Estratégica do Empreendedorismo - Uma proposta de metodologia de análise de ecossistemas. Tese (Doutorado) - Universidade Estadual de Campinas, Administração, Unicamp, 2011.

LIPOMI, D.J. Video for Active and Remote Learning. Trends in Chemistry, 2(6), p. 483485, 2020.

MOREIRA, J. A. M.; HENRIQUES, S.; BARROS, D. Transitando de um ensino remoto emergencial para uma educação digital em rede, em tempos de pandemia. Rev. Dialogia, São Paulo, n. 34, p. 351-364, 2020

MOREIRA, A. J.; SCHLEMMER, E. Por um novo conceito e paradigma de educação digital online. Revista UFG, 20(26). Disponível em: https://doi.org/10.5216/revufg.v20.63438 (2020). Acesso em: set/2020

OLIVEIRA, V. F. As inovações nas atuais diretrizes para a Engenharia: estudo comparativo com as anteriores. In: OLIVEIRA, V. F. (org.). A Engenharia e as novas DCNs: oportunidades para formar mais e melhores engenheiros. Rio de Janeiro: LTC, 2019.

PRETTO, N. de L. (Org.). Tecnologia e novas Educações. Salvador/Bahia: Edufba, 2005. v. $1,230 \mathrm{p}$.

SCHAEFER, R., MINELLO,I.F. Educação Empreendedora: premissas, objetivos e metodologias. Rev. Pensamento Contemporâneo em Administração 10, 2016. 
SCHWETZ, P. F. et al. Ensino Remoto Emergencial: desafios e estratégias para a retomada. Disponível em: https://lume.ufrgs.br/handle/10183/212562. Acesso em: set/2020

VERZAT, C., BACHELET, R. Developing an Entrepreneurial Spirit among engineering college students: what are the educational factors?. International Entrepreneurship Education 11, 2006.

TORREZAN, Cristina Alba Wildt. Modelo para avaliação de desenvolvimento da habilidade espacial em desenho técnico(MADHE).2019. Tese(Doutorado em Design) Escola de Engenharia, Universidade Federal do Rio Grande do Sul, Porto Alegre, 2019.

VU, C.T.; HOANG, A. D; THAN, V.Q; NGUYEN, M.T; DINH, V.H; LE, Q.A. T; LE, T.T.T.; PHAM, H.H.; NGUYEN, Y.C. Dataset of Vietnamese teachers' perspectives and perceived support during the COVID-19 pandemic. Data in Brief, 31(1), p.1-9, 2020.

YIN, R. K. Estudo de caso: planejamento e métodos. 5. ed. Porto Alegre: Bookman, 2015 ZANCUL, E; MACUL, V.; MAJZOUB, G.; BLIKSTEIN, P.; LOPES, R. D.; SCHEER, S. 0 cenário atual da disciplina de Introdução à Engenharia no Brasil: uma oportunidade a ser aproveitada. Research and Innovation in Brazilian Education, ISSN 2473-2621, Ano III - $\mathrm{N}^{\circ} \mathrm{I}$ - janeiro de 2018.

\section{EMERGENCY REMOTE EDUCATION IN ENGINEERING AND TECHNOLOGY COURSES}

Abstract: With the advent of the pandemic caused by COVID-19 in 2020, Higher Education Institutions (HEls) had to adapt to continue academic activities and implement teaching models to put into practice what the Ministry of Education (ME) called Emergency Remote Education (ERE). The challenges posed by the pandemic in 2020 were a milestone for teachers and institutions, especially with regard to proposing and adapting teaching in Engineering and Technology courses, and imposed the immediate need to become aware and test - in the best of its possibilities - models implemented in different institutions. The aim of this work is to discuss and evaluate whether these initiatives were successful, that is, whether there was understanding and good performance of teachers and students about the new way of learning and teaching, studying and planning the disciplines. To this do so, a survey was conducted through a questionnaire applied to several Higher Education Institutions (HEls) with a total of 124 respondents who made it possible to conclude that both the teacher and the student have the potential and responsibility to transform teaching, in addition to aligning and potentiating the use of innovations in remote classes.

Keywords: Education. Engineering. ERE. 